\title{
Comparison of continuous epidural infusion and programmed intermittent epidural bolus in labor analgesia
}

This article was published in the following Dove Press journal:

Therapeutics and Clinical Risk Management

14 July 2016

Number of times this article has been viewed

\section{Yunan Lin \\ Qiang Li \\ Jinlu Liu \\ Ruimin Yang \\ Jingchen Liu}

Department of Anesthesiology, The First Affiliated Hospital of Guangxi Medical University, Nanning, Guangxi, People's Republic of China
Correspondence: Jingchen Liu Department of Anesthesiology, The First Affiliated Hospital of Guangxi Medical University, No 6 ShuangYong Road, Nanning, Guangxi 53002I, People's Republic of China

Tel +86 77I 5356250

Email liujchengx@yeah.net
Background: This study aims to investigate differences between continuous epidural infusion (CEI) and programmed intermittent epidural bolus (IEB) analgesia for the Chinese parturients undergoing spontaneous delivery and to approach their safety to parturients and neonates.

Methods: Two hundred healthy American Society of Anesthesiologists class I or II, term ( $\geq 37$ weeks' gestation), nulliparous women who requested analgesia for labor were recruited. Epidural analgesia was initiated with a solution of $0.15 \%$ ropivacaine $10 \mathrm{~mL}$ and maintained with $0.1 \%$ ropivacaine mixed with sufentanil $0.3 \mu \mathrm{g} / \mathrm{mL}$ by CEI at a rate of $5 \mathrm{~mL} / \mathrm{h}$ combined with a patient-controlled epidural analgesia (PCEA) bolus of $5 \mathrm{~mL}$ of ropivacaine sufentanil mixture or IEB of $5 \mathrm{~mL}$ of ropivacaine sufentanil mixture combined with a PCEA bolus of $5 \mathrm{~mL}$ of ropivacaine sufentanil mixture. The lockout interval was 20 minutes in each arm between the CEI and the IEB group. After 20 minutes of first dosage, visual analog scale (VAS) score was obtained every 60 minutes. The maternal and fetal outcome and total consumption of analgesic solution were compared.

Results: There was no difference in demographic characteristics, duration of first and second stages, delivery methods, sensory block, fetal Apgar scores, and the maternal outcomes between the CEI and IEB groups. There was a significant difference in VAS scores and epidural ropivacaine total consumption between the two groups (IEB vs CEI: $51.27 \pm 9.61$ vs $70.44 \pm 12.78 \mathrm{mg}$, $P<0.01)$.

Conclusion: The use of programmed IEB mixed with PCEA improved labor analgesia compared to CEI mixed with PCEA, which could act as maintenance mode for epidural labor analgesia. Keywords: intermittent epidural bolus, continuous epidural infusion, labor analgesia, patientcontrolled epidural analgesia

\section{Introduction}

Labor pain is a unique pain for parturients; in the past, people regarded it as normal and unavoidable. Since the development of anesthesia from 1846, people's demand for better quality of life increased, and a feasible labor analgesia mode has been searched for one and a half centuries. In 1995, World Health Organization identified the goal of universal high-quality reproductive health as a global target by 2015. Pregnancy and delivery is an important part of reproductive health. ${ }^{1}$ Various techniques to provide analgesia in labor are used in clinical practice throughout the world with varying levels of success. Analgesia in labor aims to reduce parturients' pain during delivery by different methods, including drugs,${ }^{2}$ local anesthesia, and epidural analgesia. ${ }^{3}$ Adequate analgesia in labor can decrease the adverse impacts, which can result from inadequately controlled labor pain, on the mother and the fetus. ${ }^{4}$ 
The generally used analgesia in labor mainly includes the continuous epidural infusion (CEI) and programmed intermittent epidural bolus (IEB) analgesia. However, there are controversial findings for the usage of the CEI and IEB analgesia methods, and the neuraxial labor analgesia has been a contentious issue for labor analgesia. Meanwhile, randomized controlled trials have suggested that neuraxial labor analgesia is the most feasible and acceptable labor analgesia method. ${ }^{3}$ Although it does not increase the risk of cesarean delivery, its impact on operative vaginal delivery and other parturient safety outcomes is still controversial. ${ }^{5}$ This study mainly aims to investigate whether there are any differences between CEI and programmed IEB analgesia for the Chinese parturients undergoing spontaneous delivery and to further investigate the safety of these techniques for parturients and neonates.

\section{Materials and methods}

\section{General information}

This study was approved by the Ethical Committee of Human Research of the First Affiliated Hospital of Guangxi Medical University, Nanning, People's Republic of China. Two hundred healthy American Society of Anesthesiologists physical status I or II, term ( $\geq 37$ weeks' gestation), nulliparous women in early spontaneous labor pain having at least one uterine contraction every 5 minutes and who had requested neuraxial block were recruited for the study. Each of the parturients gave written informed consent to participate in the study. Exclusion criteria included the presence of systemic disease (eg, diabetes mellitus, hypertension, and preeclampsia) and chronic analgesic use, multiple pregnancies, or preterm labor. At the time of request for labor analgesia, the cervix was examined by a midwife. If cervical dilation was between 2 and $4 \mathrm{~cm}$, parturients were enrolled in our study and randomly allocated using a sealed envelope technique to receive the maintenance of analgesia by either IEB (Group IEB, n=102) mixed with patientcontrolled epidural analgesia (PCEA) or CEI (Group CEI, $\mathrm{n}=98$ ) mixed with PCEA. The subjects and other attendants were blinded to group assignment. When the cervical dilation was completed, epidural analgesia was discontinued in all parturients.

\section{Analgesia}

Epidural analgesia was initiated in the left lateral decubitus position at the $\mathrm{L}_{3-4}$ interspace by using loss-of-resistance technique to identify the epidural space. An epidural catheter was placed $3-3.5 \mathrm{~cm}$ into the epidural space in a cephalic direction. After the placement of the epidural catheter, an intravenous infusion of $500 \mathrm{~mL}$ Ringer lactate solution was commenced and the visual analog scale (VAS) score for the baseline pain of uterine contraction was determined. Baseline maternal heart rate, noninvasive arterial blood pressure, and fetal heart rate (FHR) tracing were recorded.

All parturients received a $4 \mathrm{~mL}$ test dose of $1 \%$ lidocaine. Five minutes later, the initial loading dosage consisting of $0.15 \%$ ropivacaine $10 \mathrm{~mL}$ was injected. Parturients whose VAS score was not at least 1 or lower than the baseline within 30 minutes after the epidural injection or who requested a PCEA bolus within 30 minutes were considered to have a failed block and were excluded from the study and subsequent statistical analysis. After the first dose and the exact effect of epidural analgesia were assessed, a sequentially numbered, opaque envelope containing the group assignment was opened by an unblinded researcher who set up the two epidural pumps according to the group allocation. The subjects and other study personnel were blinded to the group assignment and all the observations and assessments were performed by a researcher blinded to the mode of drug administration. The infusion pumps were put into an opaque, portable bag. The maintenance epidural solution for the two groups consisted of $0.1 \%$ ropivacaine mixed with sufentanil $0.3 \mu \mathrm{g} / \mathrm{mL}$; two pumps were prepared for each subject with the same epidural solution. One pump was programmed to administer with CEI at a rate of $5 \mathrm{~mL} / \mathrm{h}$ and mixed with a PCEA bolus of $5 \mathrm{~mL}$ whenever the parturient felt uncomfortable because of uterine contraction; lockout interval was set to 20 minutes. The second pump was programmed with an hourly IEB of $5 \mathrm{~mL}$ and mixed with a PCEA bolus of $5 \mathrm{~mL}$, lockout interval was $20 \mathrm{~min}$ utes, basal infusion rate was $0 \mathrm{~mL} / \mathrm{h}$, and maximum total dosage of all pumps was $15 \mathrm{~mL} / \mathrm{h}$. Each of the parturients was instructed to push the PCEA demand button whenever she felt uncomfortable.

\section{Observation items}

Commencing 20 minutes after the first dosage, the VAS score (0-100) was assessed every 60 minutes, and the sensory was assessed hourly based on the modified Bromage scale ( $0-3,0$ : no motor block; 1: inability to raise extended leg, able to move knees and feet; 2 : inability to raise extended leg and move knee, able to move feet; 3 : complete block of motor limb). The active intervals of labor, the delivery time, the mode of delivery (vaginal delivery, assisted/instrumental vaginal delivery, cesarean delivery), the FHT during the 
delivery, and Apgar scores at 1 and 5 minutes were recorded for patients in each arm of the study. At the same time, the VAS scores (at baseline and then every 60 minutes), the epidural infusions including delivered PCEA boluses, and total epidural infused volumes from the infusion pumps were recorded.

\section{Statistical analysis}

Data were processed using SPSS Version 13.0 (SPSS Inc., Chicago, IL, USA). The results were expressed as mean \pm standard deviation. Differences between the two groups were analyzed by Student's $t$-test. $P$-values less than 0.05 were considered as statistically significant.

\section{Results}

\section{Basic properties and maternal and fetal outcomes}

A total of 200 patients were recruited to the study and randomized to either the IEB or the CEI group. Three subjects were excluded from the analysis because of unplanned epidural catheter removal. There was no statistically significant difference between the two groups with regard to patient characteristics (Table 1). There was no significant difference in the maternal and fetal outcomes, and in the duration time of the first and second stage of labor in the IEB and CEI groups (Table 2).

\section{Characteristics of labor analgesia}

There was a significant difference in the epidural ropivacaine total consumption between the two groups $51.27 \pm 9.61 \mathrm{mg}$ in the IEB group vs $70.44 \pm 12.78 \mathrm{mg}$ in the CEI group $(P=0.00)$ (Table 3; Figure 1).

\section{VAS scores for IEB and CEI groups}

The consumption of epidural ropivacaine of two groups was within the normal dose range. The baseline VAS scores and time of pain relief and bilateral block to T10 obtained after the initial bolus were not significantly different. However, the VAS scores of the IEB group were lower than those of the CEI group at a later stage (Figure 2).

\section{The FHT for both groups}

The parturients' blood pressure and heart rates were comparable between the two groups when examined at the same time. There was no significant difference in the parturients' blood pressure, heart rates, and the FHTs during the delivery (Figure 3).

\section{Discussion}

In this study, we compared the CEI with the programmed IEB analgesia for the Chinese parturients undergoing spontaneous delivery and investigated their safety to parturients and neonates. The findings indicated that there was no difference in demographic characteristics, duration of stages, delivery methods, sensory block, fetal Apgar scores, and the maternal outcomes between the CEI and IEB groups. There was a significant difference in the VAS scores and epidural ropivacaine total consumption between the two groups.

Ropivacaine has a high threshold for cardiovascular toxicity; it had been reported that low concentration of ropivacaine is extremely safe and effective for labor delivery analgesia. ${ }^{6,7}$ Ropivacaine does not possess any sort of clinical importance, and therefore was used in the experiments. In this study, effective initial pain relief was achieved in both groups, possibly because we used $1 \%$ lidocaine $4 \mathrm{~mL}$ as a test dose and $0.15 \%$ ropivacaine $10 \mathrm{~mL}$ as an initial loading dosage. The $0.15 \%$ ropivacaine $10 \mathrm{~mL}$ was used as an initial loading dosage to ensure an adequate analgesic effect. This is confirmed by the VAS score changes pre- and postinitiation of analgesia (Figure 1). For the maintenance of labor analgesia, $0.1 \%$ ropivacaine mixed with sufentanil $0.3 \mu \mathrm{g} / \mathrm{mL}$ was used. This provided satisfactory analgesia for the parturients as shown in Figure 1. However, in this study, the VAS scores of IEB group were lower than in the CEI group during the maintenance of labor analgesia; this may be attributed to the influence of different modes (IEB or CEI)

Table I Demographic properties, cervical dilation, and VAS scores

\begin{tabular}{|c|c|c|c|}
\hline Characteristics & IEB group & CEI group & P-value \\
\hline Age (years) & $27.45 \pm 4.61$ & $28.16 \pm 4.679$ & 0.69 \\
\hline Gestational age (weeks) & $39.12 \pm 0.81$ & $38.84 \pm 0.76$ & 0.34 \\
\hline Body mass index $\left(\mathrm{kg} / \mathrm{m}^{2}\right)$ & $28.35 \pm 1.42$ & $28.54 \pm 1.51$ & 0.61 \\
\hline Cervical dilation at initiation of analgesia $(\mathrm{cm})$ & $2.93 \pm 0.21$ & $3.02 \pm 0.30$ & 0.17 \\
\hline Baseline VAS scores & $7.21 \pm 0.52$ & $6.94 \pm 0.55$ & 0.08 \\
\hline
\end{tabular}

Note: Values presented as mean \pm standard error of the mean.

Abbreviations: CEI, continuous epidural infusion; IEB, intermittent epidural bolus; VAS, visual analog scale. 
Table 2 Maternal and fetal outcome

\begin{tabular}{|c|c|c|c|}
\hline Characteristics & IEB group & CEI group & P-value \\
\hline Delivery mode (cesarean/instruments/NSVD) & $8 / 10 / 98$ & $10 / 9 / 99$ & - \\
\hline Duration of first stage of labor (minutes) & $420.35 \pm 20.29$ & $431.51 \pm 19.09$ & 0.75 \\
\hline Duration of second stage of labor (minutes) & $55.31 \pm 9.7 I$ & $58.53 \pm 8.19$ & 0.68 \\
\hline Apgar score at I minute & $8.62 \pm 0.29$ & $8.57 \pm 0.16$ & 0.64 \\
\hline Apgar score at 5 minutes & $9.03 \pm 0.18$ & $9.13 \pm 0.16$ & 0.06 \\
\hline
\end{tabular}

Note: Values presented as mean \pm standard deviation.

Abbreviations: CEI, continuous epidural infusion; IEB, intermittent epidural bolus; NSVD, normal, spontaneous vaginal delivery.

of anesthetic infusion. Actually, there are many different CEI and IEB dosing regimens that vary between different obstetric anesthesia providers and practices. Although the dosing regimens used in our study were relatively lower, they were based on the practice at our institute. Furthermore, we found that the same results have also been appreciated at a higher hourly infusion rate.

Epidural labor analgesia is popular but the risk of numbness, pain breakthrough, need for epidural top-ups, ${ }^{8}$ maternal and fetal outcomes, delivery mode, and neonatal Apgar scores need to be taken into consideration. In this study, there was no significant difference in the numbness, breakthrough top-ups, maternal and fetal outcomes, delivery mode, and neonatal Apgar scores between the two groups. This could possibly be attributed to the low concentration of local anesthetic $(0.1 \%$ ropivacaine) used with a low dose of opioid (sufentanil $0.3 \mu \mathrm{g} / \mathrm{mL}$ ) used in the local anesthetic mixture. This may also have been responsible for the high quality of analgesia and a lack of change in blood pressure at the first or second delivery stages in our study. This observation can be attributed to the characteristics of sensory and motor isolation of ropivacaine when used in low concentration. ${ }^{6}$

In this study, there was a significant difference in the epidural ropivacaine total consumption between the two groups; the programmed intermittent bolus (hourly bolus) group resulted in less epidural drug use. In order to exclude the influences of the analgesia methods, we used the PCEA to perform the experiment. As the labor progressed, the VAS scores in the IEB group were lower when compared with those of the CEI group with the same mixed solution of ropivacaine and sufentanil. This may be associated with the rate of injection which is one of the factors influencing epidural blocked segments. ${ }^{9}$ Researches on both cadaveric dissection and clinical study showed that a greater efficacy of bolus injection of local anesthetics occurs with a faster rate of injection. ${ }^{10}$ Another probability is a greater spread of infusate from a multiorificed catheter. ${ }^{11}$ Experiments have shown that when intermittent boluses were used instead of a continuous infusion, despite a similar rate of infusion, a greater spread of infusate from a multiorificed catheter was found in intermittent boluses. ${ }^{12}$ In this study, we attributed the lower total consumption of local anesthetic in the IEB group to a more uniform spread of local anesthetic in the epidural space when compared with the CEI group. Moreover, when using a continuous infusion, there was practically no flow through the distal hole, whereas when intermittent bolus was used, the infusate would flow out from all the holes. Also in the studies by Hogan and Lim et al, cryomicrotome sectioning showed uniform spread of liquid in the epidural space through the intervertebral foraminae and along the nerve sheaths when using large volumes of injection and a high injection pressure. ${ }^{10,13}$ This theory may support the observation of lower VAS scores in the IEB group in our study. Based on this theory, we hypothesized that IEB injecting local anesthetic can achieve a better epidural block height and a slower sensory block regression than the CEI group. This was consistent with lower VAS scores and less requirement of rescue medication by PCEA in the IEB group $(1.27 \pm 0.26$ vs $5.71 \pm 1.03)$. In this study, we recorded parturients' selfadministration of local anesthetic according to their levels of pain by PCEA. Parturients demanded a PCEA when the sensory block regressed. This study aimed to compare the

Table 3 Characteristics of labor analgesia

\begin{tabular}{llll}
\hline Characteristics & Intermittent group & Continuous group & $P$-value \\
\hline Dosage consumption of ropivacaine $(\mathrm{mg})$ & $51.27 \pm 9.61$ & $70.44 \pm 12.78$ & $0.00^{*}$ \\
Rescue medication dose by PCEA $(\mathrm{mg})$ & $1.27 \pm 0.26$ & $5.71 \pm 1.03$ & $0.00^{*}$ \\
Time to reach maximum block height (TI0) (minutes) & $12.7 \pm 2.6$ & $12.2 \pm 2.3$ & 0.62 \\
\hline
\end{tabular}

Notes: Values were presented as mean \pm standard deviation. $* P<0.05$ when the groups were compared.

Abbreviation: PCEA, patient-controlled epidural analgesia. 


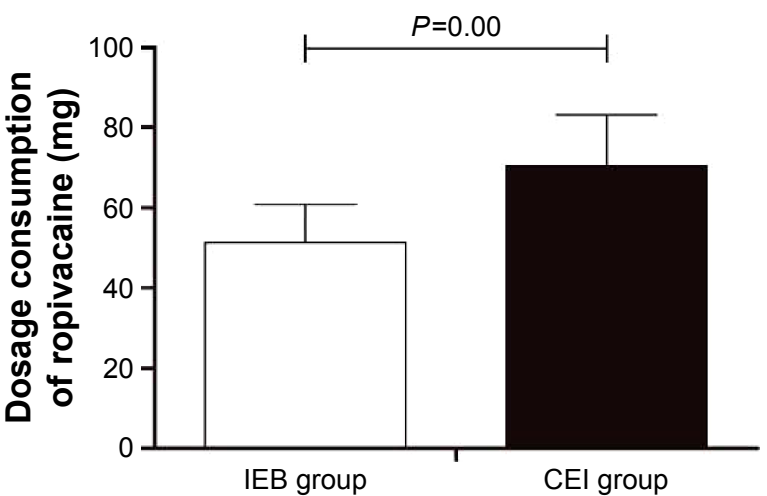

Figure I Consumption of ropivacaine in two groups.

Abbreviations: CEl, continuous epidural infusion; IEB, intermittent epidural bolus.

effects of PIB and CEI, and we have considered the women's demands. All of the women agreed that the PCEA increased the satisfaction and inhibited the drug metabolism. The IEB administration group seldom needed PCEA, and this may be attributed to the programmed IEB (hourly bolus) which can provide a higher injection pressure and more uniform spread of local anesthetic in the epidural space than CEI. The metabolism of local anesthetics should also be taken into consideration. In the IEB group, $5 \mathrm{~mL}$ local anesthetic was given by hourly bolus while in the CEI group the anesthetic was infused over 1 hour, thus allowing more time for the metabolism of the drug. The superior block height and slower sensory block regression observed in the IEB group may have been due to differences in the rates of metabolism in each technique. Reduced PCEA boluses also resulted in less epidural drug use. Our results indicated that there was a significant difference in VAS scores and epidural ropivacaine total consumption between the two groups. From the results presented in Tables 2 and 3 and Figure 2, we could speculate that the programmed IEB mixed with PCEA is

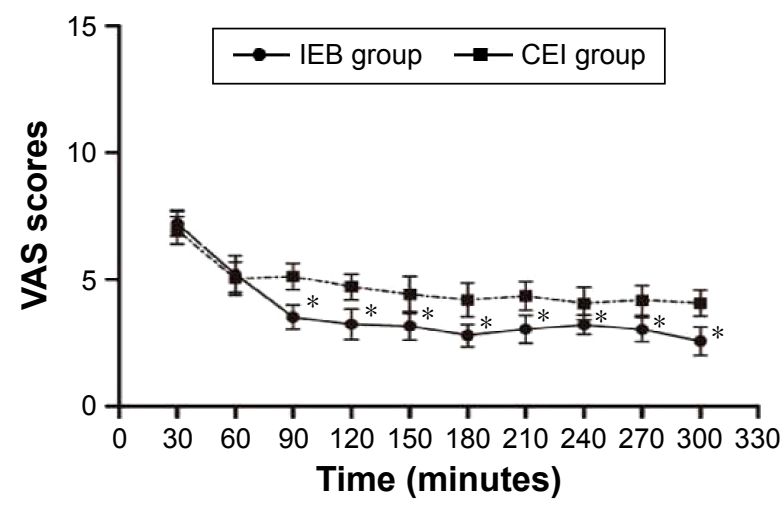

Figure 2 The VAS scores for the groups (mean \pm standard error of the mean). Note: $* P<0.05$ when the groups were compared.

Abbreviations: VAS, visual analog scale; CEI, continuous epidural infusion; IEB, intermittent epidural bolus.

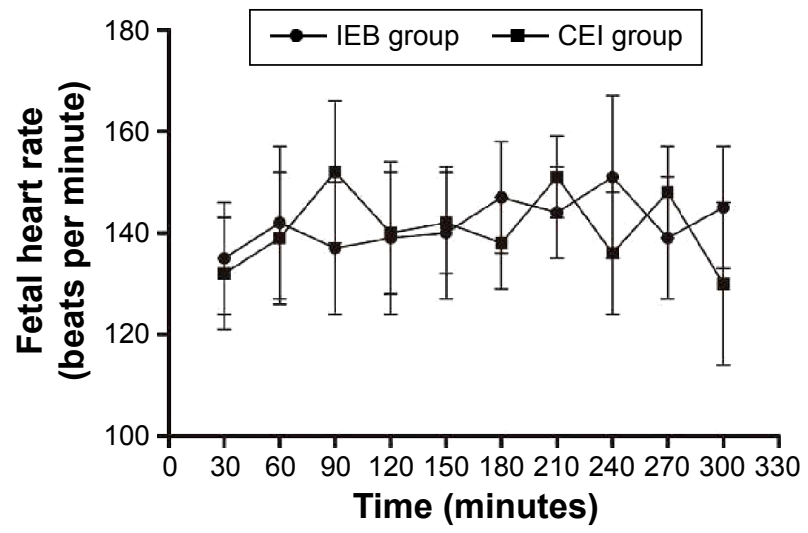

Figure 3 The FHT for both groups.

Note: Error bars represent standard deviation

Abbreviations: FHT, fetal heart rate; CEI, continuous epidural infusion; IEB, intermittent epidural bolus.

relatively effective. Some researchers showed that epidural labor analgesia prolonged the labor stage and increased the usage of instruments. ${ }^{14-18}$ However, in this study, labor stages were shortened and there was no significant difference in labor instruments usage when compared with normal labor. We assumed that oxytocin use during the delivery and discontinuation of analgesia during the second stage might play an important role.

Though we have received some valuable results, there are also some limitations. First, several factors could influence the outcome of the results of the comparison between CEI and the programmed IEB in labor analgesia. In future studies, we would investigate the factors affecting the differences of the two methods. Second, only the PCEA method was used in this study, which may not fully describe the status of the patients undergoing the CEI and programmed IEB analgesia. Third, we have not involved the primary outcome of the patients and only involved 200 women without identified outcome. Fourth, the manual boluses have not been counted as part of the total local anesthetic dose. Moreover, the FHT charted at a given point in time does not provide the information on the presence of late or variable FHT decelerations or the variability of FHT. Therefore, we would investigate in detail the variable FHT decelerations.

\section{Conclusion}

In conclusion, the use of programmed IEB combined with PCEA improved labor analgesia compared to the CEI mixed with PCEA, and this technique could be more useful as the mode of maintenance for epidural labor analgesia.

\section{Disclosure}

The authors report no conflicts of interest in this work. 


\section{References}

1. Serour GI. Reproductive and sexual health rights: 15 years after the International Conference on Population and Development. Int J Gynecol Obstet. 2009;106:99-101.

2. Karhade SS, Sardesai SP. $0.2 \%$ ropivacaine with fentanyl in the management of labor analgesia: a case study of 30 parturients. Anesth Essays Res. 2015;9(1):83-87.

3. Flick RP, Lee K, Hofer RE, et al. Neuraxial labor analgesia for vaginal delivery and its effects on childhood learning disabilities. Anesth Analg. 2011;112(6):1424-1431.

4. Hawkins JL. Epidural analgesia for labor and delivery. $N$ Engl J Med. 2010;362(16):1503-1510.

5. Halpern SH, Abdallah FW. Effect of labor analgesia on labor outcome. Curr Opin Anesthesiol. 2010;23(3):317-322.

6. Brydone AS, Souvatzoglou R, Abbas M, Watson DG, McDonald DA, Gill AM. Ropivacaine plasma levels following high-dose local infiltration analgesia for total knee arthroplasty. Anaesthesia. 2015;70(7): 784-790.

7. Chen SH, Liou SC, Hung CT, et al. Comparison of patient-controlled epidural analgesia and continuous epidural infusion for labor analgesia. Chang Gung Med J. 2006;29:576-582.

8. Pandya ST. Labour analgesia: recent advances. Indian J Anaesth. 2010;54(5):400-408.

9. Leone Roberti Maggiore U, Silanos R, Carlevaro S, et al. Programmed intermittent epidural bolus versus continuous epidural infusion for pain relief during termination of pregnancy: a prospective, double-blind, randomized trial. Int J Obstet Anesth. 2016;25(1):37-44.
10. Hogan Q. Distribution of solution in the epidural space: examination by cryomicrotome section. Reg Anesth Pain Med. 2002;27(2):150-156.

11. Hogan Q. Epidural catheter tip position and distribution of injectate evaluated by computed tomography. Anesthesiology. 1999;90(4):964-970.

12. Kaynar AM. Epidural infusion: continuous or bolus? Anesth Analg. 1999;89(2):534-534.

13. Lim Y, Sia A, Ocampo C. Automated regular boluses for epidural analgesia: a comparison with continuous infusion. Int J Obstet Anesth. 2005;14(4):305-309.

14. Sharma SK, McIntire DD, Wiley J, Leveno KJ. Labor analgesia and cesarean delivery: an individual patient meta-analysis of nulliparous women. Anesthesiology. 2004;100(1):142-148.

15. Woo JH, Kim JH, Lee GY, et al. The degree of labor pain at the time of epidural analgesia in nulliparous women influences the obstetric outcome. Korean J Anesthesiol. 2015;68(3):249-253.

16. George RB, Allen TK, Habib AS. Intermittent epidural bolus compared with continuous epidural infusions for labor analgesia: a systematic review and meta-analysis. Anesth Analg. 2013;116(1):133-144.

17. Capogna G, Camorcia M, Stirparo S, Farcomeni A. Programmed intermittent epidural bolus versus continuous epidural infusion for labor analgesia: the effects on maternal motor function and labor outcome. Anesth Analg. 2011;113(4):826-831.

18. Wong CA, Ratliff JT, Sullivan JT, Scavone BM, Toledo P, McCarthy RJ. A randomized comparison of programmed intermittent epidural bolus with continuous epidural infusion for labor analgesia. Anesth Analg. 2006;102:904-909.
Therapeutics and Clinical Risk Management

\section{Publish your work in this journal}

Therapeutics and Clinical Risk Management is an international, peerreviewed journal of clinical therapeutics and risk management, focusing on concise rapid reporting of clinical studies in all therapeutic areas, outcomes, safety, and programs for the effective, safe, and sustained use of medicines. This journal is indexed on PubMed Central, CAS,

\section{Dovepress}

EMBase, Scopus and the Elsevier Bibliographic databases. The manuscript management system is completely online and includes a very quick and fair peer-review system, which is all easy to use. Visit http://www.dovepress.com/testimonials.php to read real quotes from published authors. 